\title{
PERANCANGAN ALAT ANGKAT KEMASAN SUSU BUBUK MEMPERHATIKAN ASPEK ERGONOMI DAN ANTRHOPOMETRI
}

\author{
Agus Priyanto ${ }^{1}$, Masrul Indrayana ${ }^{2}$, Ilmardani Rince Ramli ${ }^{3}$ \\ 1,2,3Teknik Industri, Fakultas Teknik \\ Universitas Widya Mataram, Yogyakarta, Indonesia \\ e-mail: 1agoessgm1@gmail.com, ${ }^{2}$ masrul_indrayana@yahoo.com
}

Diterima: 18 September 2019. Disetujui : 12 Nopember 2019. Dipublikasikan : 30 Desember 2019

(C)2019 -TESJ Fakultas Teknik Universitas Maarif Hasyim Latif. Ini adalah artikel dengan

akses terbuka di bawah lisensi CC BY 4.0 (https://creativecommons.org/licenses/by/4.0/)

\begin{abstract}
ABSTRAK
PT. Sarihusada Generasi Mahardhika (PT. SGM) memiliki aktivitas pemindahan material manual (Material Manual Handling) oleh operator produksi pada pengujian hasil perekatan kemasan susu bubuk $25 \mathrm{~kg}$. Aktivitas ini menguji hasil perekatan dengan cara mengangkat kemasan zak dari area perekatan dibawa ke tempat pengujian dengan cara diangkat langsung oleh operator. Penelitian ini bertujuan untuk merancang alat bantu angkat untuk meningkatkan produktivitas kerja operator. Rancangan alat bantu dibangun berdasarkan analisis beban mental, gerakan kerja dan keluhan kesakitan operator. Pengukuran beban mental dilakukan dengan menggunakan metode NASA-TLX. Penilaian postur dan pergerakan kerja menggunakan metode REBA. Sedangkan untuk penilaian kelelahan fisik/musculoskeletal disease (MSDs) menggunakan kuesioner NBM (Nordic Body Map). Penerapan alat bantu angkat yang telah dirancang ternyata dapat membantu operator dan menaikkan produktivitas kerja sebesar $23 \%$.
\end{abstract}

Kata kunci: aktivitas pengujian hasil rekatan, nasa-tlx, nbm, alat bantu angkat manual material handling, reba

\section{PENDAHULUAN}

PT. Sarihusada Generasi Mahardhika (SGM) Yogyakarta berdiri tahun 1954. SGM merupakan perusahaan yang memproduksi produk bernutrisi untuk bayi dan anak-anak Indonesia. Produknya berupa aneka susu formula untuk bayi dan makanan bernutrisi dengan standar mutu internasional. Kepedulian SGM terhadap K3 tercermin dalam kebijakan K3LH (Kesehatan, Keselamatan Kerja dan Lingkungan Hidup) dengan target kecelakaan nol atau nihil (zero accident). SGM percaya bahwa keselamatan dan kesehatan kerja merupakan hak dasar bagi setiap orang, dimana kecelakaan kerja dan penyakit akibat kerja dapat ditiadakan.

SGM memiliki program bernama WISE (Work in Safe Environment), dimana program tersebut merupakan sebuah program berkaitan dengan keselamatan dan kesehatan kerja secara menyeluruh, baik di operasional (pabrik) maupun komersial (penjualan dan distribusi). Program WISE dan K3 menjadikan dasar setiap keputusan manajemen termasuk diantaranya pada aktivitas operasi Manual Material Handling. Aktivitas Manual Material Handling yang dilakukan di departemen produksi pada mesin pengisian susu bubuk kemasan $25 \mathrm{~kg}$, berpotensi membahayakan operator di setiap periode kerja. Aktivitas ini berupa pengecekan sampling hasil perekatan dengan cara memindahkan kemasan dari area perekatan ke tempat pengujian rekatan dengan cara diangkat langsung oleh operator. Aktivitas ini rutin dilakukan setiap awal shift produksi dengan rata-rata pengambilan sampel 10 zak kemasan 25 kg. Mesin akan lanjut berproduksi jika hasil uji dinyatakan memenuhi standar kualitas.

Aktivitas memindahkan kemasan dari area perekatan ke tempat pengujian secara manual berpotensi menyebabkan kecelakaan kerja. Oleh karena itu, diperlukan alat bantu untuk mengangkat kemasan susu bubuk sehingga menghindari kecelakaan kerja.

Alat bantu kerja sudah seharusnya memperhatikan aspek pengguna alat tersebut. Alat bantu kerja harus dirancang sesuai dengan kebutuhan penggunanya (fit the task to the man). Perancangan alat bantu kerja dapat dilakukan dengan terlebih dahulu menerapkan kajian ergonomi dan anthropometri. Ergonomi merupakan cabang ilmu yang mempelajari sifat, kemampuan dan keterbatasan manusia (Sutalaksana, 2006). Penerapan ergonomi umumnya merupakan aktivitas rancang bangun ataupun rancang ulang (Nurmianto, 2003). Sedangkan anthropometri merupakan satu kumpulan data numerik yang berhubungan dengan karakteristik fisik tubuh manusia ukuran, bentuk dan kekuatan serta penerapan dari data tersebut untuk penanganan 
masalah desain (Restantin, Ushada, \& Ainuri, 2012).

Anthropometri berperan penting dalam bidang perancangan industri, perancangan pakaian, perancangan alat bantu, ergonomi, dan arsitektur. Berdasarkan hal tersebut dalam penelitian ini membahas model alat angkat kemasan susu bubuk $25 \mathrm{~kg}$ PT Sarihusada Generasi Mahardhika dengan memperhatikan aspek ergonomi dan anthropometri, serta peningkatan produktivitas kerja setelah penerapan alat bantu angkat bagi operator kemasan susu bubuk $25 \mathrm{~kg}$ PT Sarihusada Generasi Mahardhika.

\section{METODE PENELITIAN}

Analisis permasalahan dalam penelitian ini dimulai dari pengukuran beban kerja operator dengan menggunakan National Aeronautics and Space Administration Task Load Index (NASA-TLX) worksheet. Metode NASA-TLX merupakan prosedur rating multi dimensional yang membagi workload atas dasar rata-rata pembebanan enam dimensi, yaitu Mental Demand, Physical Demand, Temporal Demand, Effort, Own Performance, dan Frustation (Hart \& Staveland, 1988). NASA-TLX dibagi menjadi dua tahap, yaitu perbandingan tiap skala (Paired Comparison) dan pemberian nilai terhadap pekerjaan (Event Scoring).

Selanjutnya dilakukan penilaian tingkat resiko dari sebuh sikap kerja menggunakan metode Rapid Entire Body Assessment (REBA). REBA membagi bagian tubuh menjadi 6 bagian yaitu: trunk, neck, legs, upper arms, dan lower arms (Hignett \& McAtamney, 2000).

Untuk mengetahui kelelahan fisik/ musculoskeletal disease (MSDs) operator pengisian susu kemasan $25 \mathrm{~kg}$ dilakukan dengan menggunakan kuesioner Nordic Body Map (NBM). Kuisioner NBM merupakan kuisioner yang paling sering digunakan untuk mengetahui ketidaknyamanan atau kesakitan pada bagian tubuh. Instrumen NBM yang terdiri dari 27 items pertanyaan sudah biasa digunakan terutama untuk penelitian ergonomi (Soewarno, 2005).

Setelah seluruh informasi NASA-TLX, REBA dan MSDs diperoleh, selanjutnya dilakukan perancangan alat bantu kerja dengan memperhatikan aspek ergonomi dan dimensi ukuran antrhopometri operator. Alat bantu kerja yang dirancang kemudian diujicobakan kepada operator. Produktivitas kerja operator sebelum dan sesudah penggunaan alat kemudian dibandingkan dan diuji menggunakan uji hipotesa dengan derajat keyakinan 95\%.

\section{HASIL DAN PEMBAHASAN}

SGM mempunyai unit mesin produksi diantaranya mesin pengemas susu bubuk dalam kemasan zak $25 \mathrm{Kg}$. Mesin ini berfungsi untuk mengisi susu bubuk hasil dari proses pengeringan susu cair kedalam zak kapasitas $25 \mathrm{~kg}$. Selanjutnya susu bubuk kemasan zak $25 \mathrm{~kg}$ akan dikirim ke pabrik SGM Prambanan untuk diisikan kedalam sachet atau kaleng. Setiap harinya mesin pengisian ini bisa mengemas susu bubuk rata rata sebanyak 22,5 Ton/hari yang terbagi dalam 250 zak tiap shiftnya.

Untuk melihat ketercapaian hasil produksi dilakukan pengamatan awal terhadap 4 grup pekerja yang ada di SGM. Grup 1 memproduksi rata-rata 160 zak/hari. Grup 2 memproduksi ratarata 146 zak/hari, grup 3 dan 4 memproduksi ratarata 177 zak/hari dan 160 zak/hari. Data produksi untuk setiap group pada bulan Mei dan Juni 2018 dapat disajikan seperti Gambar 1 dan Gambar 2. Grafik pencapaian jumlah kemasan zak susu 25 kg ini menginformasikan kemampuan operator produksi dalam menjalankan mesin pengisian susu dengan tambahan aktivitas pengecekan hasil perekatan dari mesin sealer.

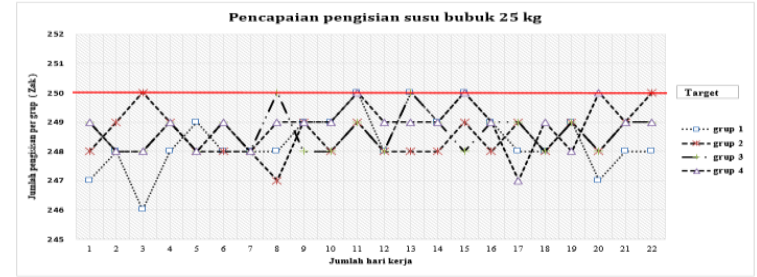

Gambar 1. Pemenuhan target produksi bulan Mei

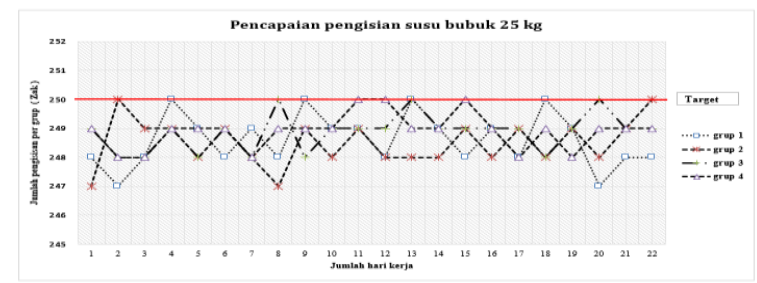

Gambar 2. Pemenuhan target produksi bulan Juni

Data NASA-TLX diperoleh dengan menyebarkan kuisioner kepada operator. Pengertian istilah-istilah dalam NASA-TLX worksheet yaitu:

1. Mental Demand. Berkaitan dengan seberapa banyak aktivitas mental dan persepsi yang diperlukan? Apakah tugas itu mudah atau menuntut keahlian khusus?

2. Physical Demand. Berkaitan dengan seberapa banyak aktivitas fisik yang diperlukan? Apakah tugas itu mudah atau menuntut keahlian khusus?

3. Temporal Demand. Berkaitan dengan seberapa banyak alokasi waktu yang anda gunakan untuk melaksanakan tugas atau elemen tugas tersebut? Apakah prosesnya lambat atau cepat? 
4. Effort. Berkaitan dengan seberapa keras anda harus bekerja (mental dan fisik) untuk mencapai tingkat kinerja anda?

5. Own Performance. Berkaitan dengan seberapa sukses anda dalam melakukan tugas?

6. Frustation: Seberapa tertekan dan jengkel dibandingkan dengan santai dan puas diri selama anda mengerjakan tugas?

Hasil perbandingan dimensi beban kerja operator berdasarkan kuisioner NASA-TLX Worksheet ditunjukkan pada Tabel 1. Jumlah tally ini kemudian menjadi bobot untuk tiap indikator beban kerja mengacu pada persamaan skor akhir beban operator. Bobot akhir pada NASA-TLX diperoleh dengan mengalikan bobot dengan rating setiap dimensi, kemudian dibagi dengan 15. Bobot akhir beban operator disajikan pada Tabel 2 . Perhitungan beban kerja operator menggunakan

Tabel 1. Hasil perbandingan dimensi beban kerja NASA-TLX

\section{NASA-TLX Scoring Worksheet}

\section{Paired-Choice (Weighting Scores)}
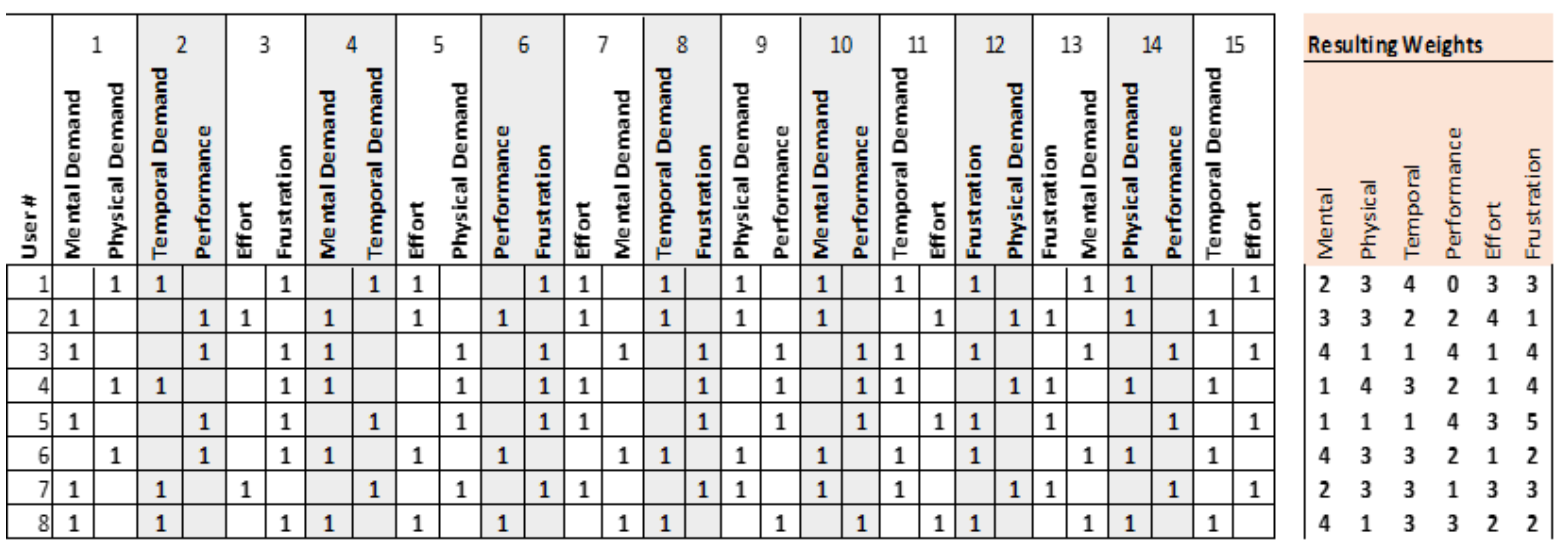

Tabel 2. Bobot akhir beban operator

\begin{tabular}{l|c|c|c|c|c|c|c|c}
\hline \multirow{2}{*}{ Faktor } & \multicolumn{2}{|c|}{ Grup 1 } & \multicolumn{2}{c|}{ Grup 2 } & \multicolumn{2}{c|}{ Grup 3 } & \multicolumn{2}{c}{ Grup 4 } \\
\cline { 2 - 9 } & Oprt 1 & Oprt 2 & Oprt 1 & Oprt 2 & Oprt 1 & Oprt 2 & Oprt 1 & Oprt 2 \\
\hline Mental demand & 45 & 50 & 35 & 45 & 40 & 30 & 40 & 55 \\
\hline Physical Demand & 55 & 55 & 60 & 55 & 55 & 60 & 55 & 55 \\
\hline Temporal Demand & 35 & 50 & 45 & 60 & 65 & 35 & 65 & 45 \\
\hline Performance & 45 & 40 & 55 & 65 & 45 & 55 & 45 & 60 \\
\hline Effort & 40 & 45 & 60 & 70 & 55 & 60 & 55 & 55 \\
\hline Frustation & 30 & 55 & 60 & 65 & 70 & 55 & 40 & 50 \\
\hline
\end{tabular}

Tabel 3. Perhitungan beban kerja operator NASA-TLX

\begin{tabular}{|c|c|c|c|c|c|c|c|c|c|c|}
\hline \multirow{2}{*}{ Faktor } & \multicolumn{2}{|c|}{ Grup 1} & \multicolumn{2}{|c|}{ Grup 2 } & \multicolumn{2}{|c|}{ Grup 3} & \multicolumn{2}{|c|}{ Grup 4} & \multirow{2}{*}{ Total } & \multirow{2}{*}{ Score } \\
\hline & Oprt 1 & Oprt 2 & Oprt 1 & Oprt 2 & Oprt 1 & Oprt 2 & Oprt 1 & Oprt 2 & & \\
\hline Mental demand & 90 & 150 & 140 & 45 & 40 & 120 & 80 & 220 & 885 & 59,00 \\
\hline Physical Demand & 165 & 165 & 60 & 220 & 55 & 180 & 165 & 55 & 1065 & $\overline{71,00}$ \\
\hline Temporal Demand & 120 & 100 & 45 & 180 & 65 & 105 & 195 & 135 & 945 & 63,00 \\
\hline Performance & 0 & 80 & 220 & 130 & 180 & 110 & 45 & 180 & 945 & 63,00 \\
\hline Effort & 180 & 180 & 60 & 70 & 165 & 60 & 165 & 110 & 990 & 66,00 \\
\hline Frustation & 210 & 55 & 240 & 260 & 350 & 110 & 120 & 100 & 1445 & 96,33 \\
\hline Total & 765 & 730 & 765 & 905 & 855 & 685 & 770 & 800 & 6275 & \\
\hline Skor akhir & 51,00 & 48,67 & 51,00 & 60,33 & 57,00 & 45,67 & 51,33 & 53,33 & & \\
\hline Rerata & & & & & & & & & & \\
\hline
\end{tabular}
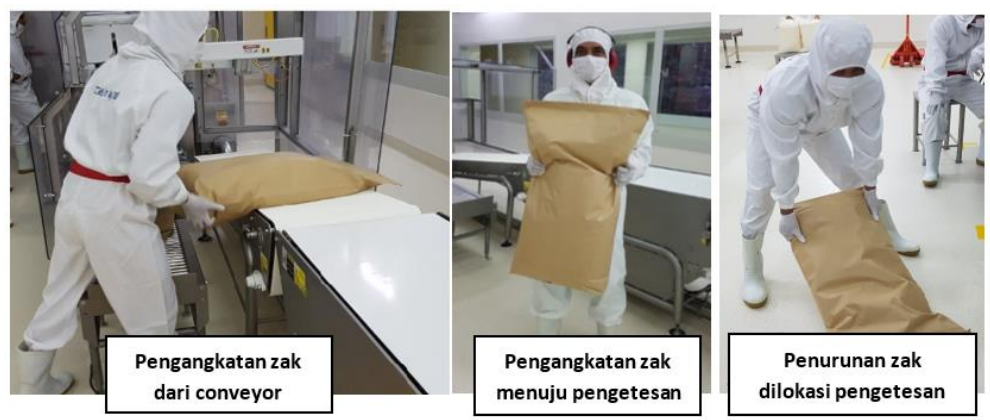

Gambar 3. Gerakan aktivitas kerja operator 
NASA-TLX Worksheet dapat disajikan pada Tabel 3. Berdasarkan Tabel 3 dimensi beban kerja mental yang dirasakan oleh keempat grup tersebut menginformasikan beban kerja operator paling banyak disebabkan oleh frustration dengan skor 96,33 dan physical demand dengan skor 71.00. Beban kerja mental yang dirasakan oleh operator salah satunya disebabkan oleh adanya aktivitas fisik yang melebihi kemampuan operator (physical demand). Kelelahan aktivitas fisik tersebut pada akhirnya berujung pada frustasi pada diri operator. Selanjutnya penilaian aktivitas kerja operator dilakukan menggunakan rekaman video. Pengecekan dilakukan awal shift sesuai prosedur dan saat terjadi kerusakan mesin sealing dan pengecekan hasil perekatan ulang setelah perbaikan. Untuk mempermudah dalam menganalisis maka rekaman video tersebut dihentikan sejenak sesuai kebutuhan, yaitu pada saat pekerja mengangkat kemasan zak dari conveyor dan membawa kemasan zak ke lokasi pengetesan hasil perekatan. Secara sederhana gerakan operator dapat dilihat pada Gambar 3.

Hasil penilaian REBA assesment worksheet

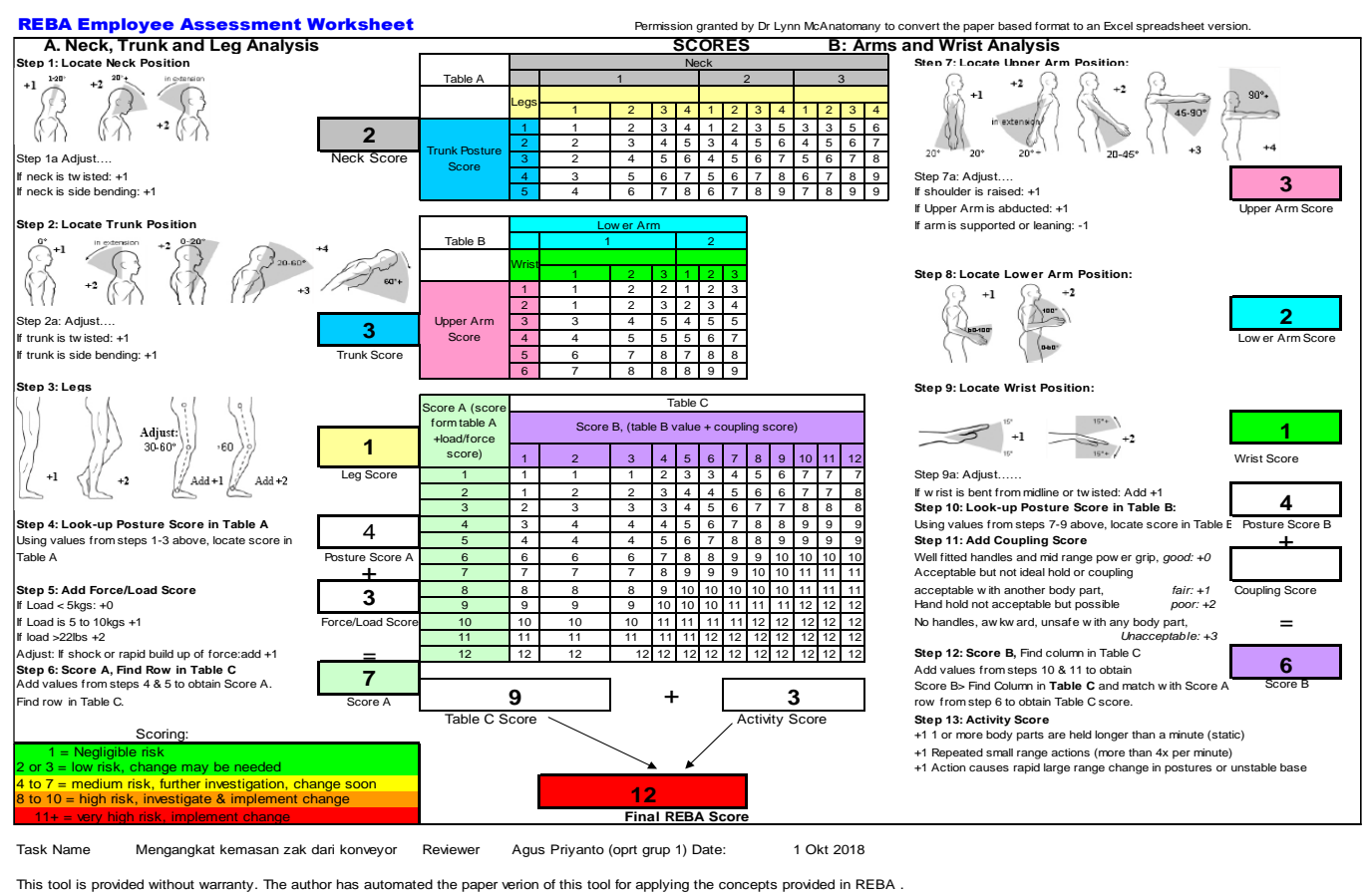

Gambar 4. Hasil penilaian REBA assesment worksheet operator

Tabel 4. Hasil penilaian REBA operator 1 group 1

\begin{tabular}{|c|c|c|c|c|c|c|c|c|c|c|c|c|c|c|}
\hline \multirow[b]{3}{*}{ Aktivitas } & \multicolumn{14}{|c|}{ REBA Assesment Worksheet operator 1 grup 1} \\
\hline & \multicolumn{6}{|c|}{ Nilai A } & \multicolumn{5}{|c|}{ Nilai B } & \multirow[b]{2}{*}{ 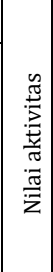 } & \multirow[b]{2}{*}{$\frac{u}{\vec{\pi}}$} & \multirow[b]{2}{*}{ 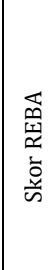 } \\
\hline & 峁 & $\begin{array}{l}\frac{\pi}{\tilde{\pi}} \\
\tilde{\varpi}\end{array}$ & $\frac{\sqrt{\pi}}{\pi}$ & 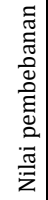 & 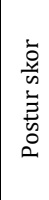 & $\begin{array}{l}\varangle \\
\frac{\pi}{\pi} \\
\bar{z}\end{array}$ & 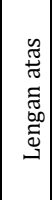 & 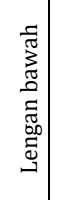 & 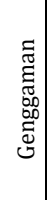 & 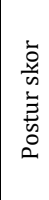 & $\frac{n}{\frac{\pi}{z}}$ & & & \\
\hline $\begin{array}{l}\text { Mengangkat kemasan zak dari } \\
\text { konveyor }\end{array}$ & 2 & 3 & 1 & 3 & 4 & 7 & 3 & 2 & 1 & 1 & 6 & 3 & 9 & 12 \\
\hline $\begin{array}{l}\text { Membawa zak ke lokasi } \\
\text { pengecekan hasil perekatan }\end{array}$ & 1 & 2 & 2 & 3 & 4 & 6 & 1 & 2 & 2 & 2 & 6 & 3 & 8 & 11 \\
\hline \multirow[t]{2}{*}{ Pengecekan hasil perekatan } & 2 & 4 & 2 & 3 & 4 & 9 & 1 & 1 & 1 & 1 & 3 & 3 & 9 & 12 \\
\hline & \multicolumn{13}{|c|}{ Rata - rata skor REBA } & 11 \\
\hline
\end{tabular}

Tabel 5. Hasil penilaian REBA seluruh operator

\begin{tabular}{|c|c|c|c|c|c|c|c|c|}
\hline & \multicolumn{2}{|c|}{ Grup 1} & \multicolumn{2}{|c|}{ Grup 2} & \multicolumn{2}{|c|}{ Grup 3} & \multicolumn{2}{|c|}{ Grup 4} \\
\hline & Oprt 1 & Oprt 2 & Oprt 1 & Oprt 2 & Oprt 1 & Oprt 2 & Oprt 1 & Oprt 2 \\
\hline Score per operator & 11 & 12 & 11 & 11 & 11 & 11 & 12 & 11 \\
\hline Score rata-rata & \multicolumn{8}{|c|}{11,25} \\
\hline REBA Score & \multicolumn{2}{|c|}{ Risk level } & \multicolumn{3}{|c|}{ Action } & \multicolumn{3}{|c|}{ Keterangan } \\
\hline 1 & \multicolumn{2}{|c|}{ Negligable } & \multicolumn{3}{|c|}{ None necessary } & \multicolumn{3}{|c|}{ Tidak perlu tindakan } \\
\hline $2-3$ & \multicolumn{2}{|c|}{ Low } & \multicolumn{3}{|c|}{ May be necessary } & \multicolumn{3}{|c|}{ Mungkin perlu tindakan } \\
\hline $4-7$ & \multicolumn{2}{|c|}{ Medium } & \multicolumn{3}{|c|}{ Necessary } & & \multicolumn{2}{|c|}{ Perlu tindakan } \\
\hline $8-10$ & \multicolumn{2}{|c|}{ High } & \multicolumn{3}{|c|}{ Necessary soon } & & \multicolumn{2}{|c|}{ Perlu tindakan segera } \\
\hline $11-15$ & \multicolumn{2}{|c|}{ Very High } & \multicolumn{3}{|c|}{ Necessary now } & \multicolumn{3}{|c|}{ Perlu tindakan sekarang } \\
\hline
\end{tabular}


operator ditunjukkan pada Gambar 4. Hasil penilaian sikap pergerakan menggunakan REBA worksheet untuk operator 1 ditunjukkan pada Tabel 4. Penilain postur kerja operator dengan metode REBA secara keseluruhan untuk seluruh operator mesin pengisian $25 \mathrm{~kg}$ disarikan pada Tabel 5.

Berdasarkan analisis REBA, sikap kerja operator pemindahan zak $25 \mathrm{~kg}$ memiliki resiko sangat tinggi (very high) sehingga memerlukan tindakan perbaikan sekarang (necessary now). Untuk itu diperlukan evaluasi dalam hal postur kerja dan perancangan alat bantu pemindahan zak yang dapat mengurangi tingkat frustasi dan kelelahan fisik operator. Perlu dipertimbangkan pengadaan alat mekanis misalnya kereta dorong untuk menghilangkan resiko cidera tulang belakang (musculoskeletal disorder). Selanjutnya untuk mengetahui dimensi kelelahan fisik/ musculoskeletal disease (MSDs) operator pengisian
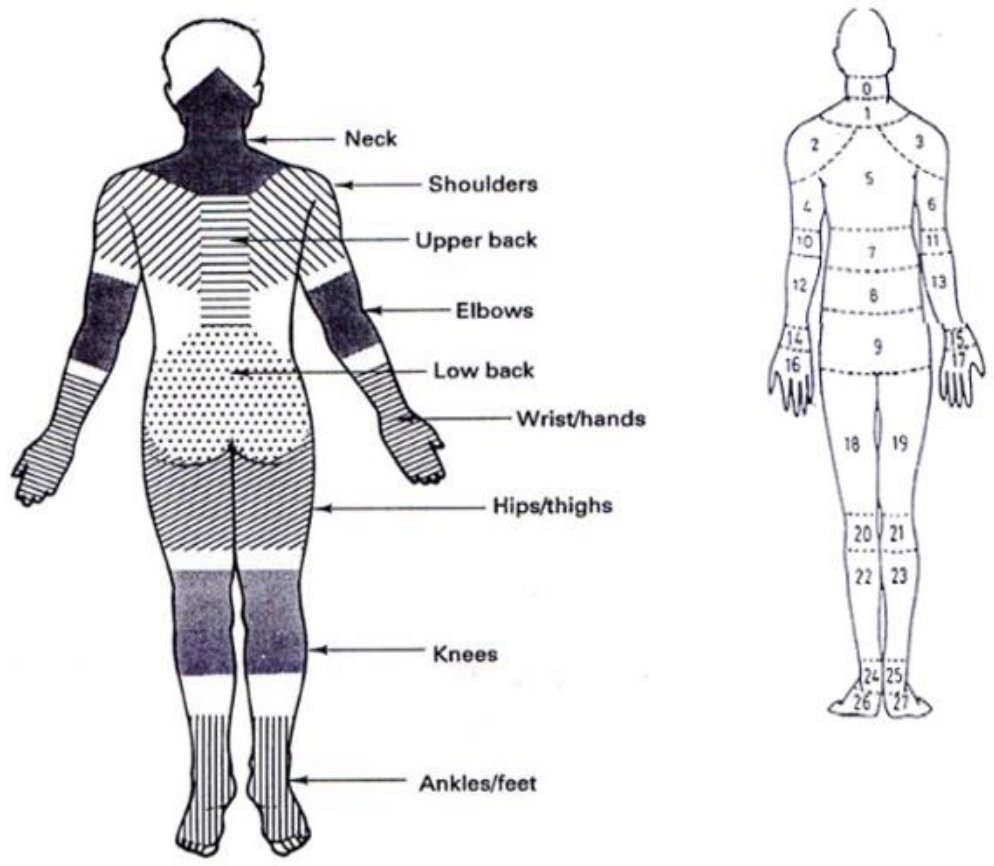

0 . Leher atas

1. Leher bawah

2. Bahu kiri

3. Bahu kanan

4. Lengan atas kir

5. Punggung

6. Lengan atas kanan

7. Pinggang

8. Bawah pinggang

9. Bokong

10. Siku kiri

11. Siku kanan

12. Lengan bawah kiri

13. Lengan bawah kanan

14. Pergelangan tangan kiri

15. Pergelangan tangan kanan

16. Tangan kiri

17. Tangan kanan

18. Paha kiri

19. Paha kanan

20. Lutut kanan

21. Lutut kiri

22. Betis kiri

23. Betis kanan

24. Pergelangan kaki kiri

25. Pergelangan kaki kanan

26. Telapak kaki kiri

27. Telapak kaki kanan

Gambar 5. Pembagian anatomi tubuh manusia

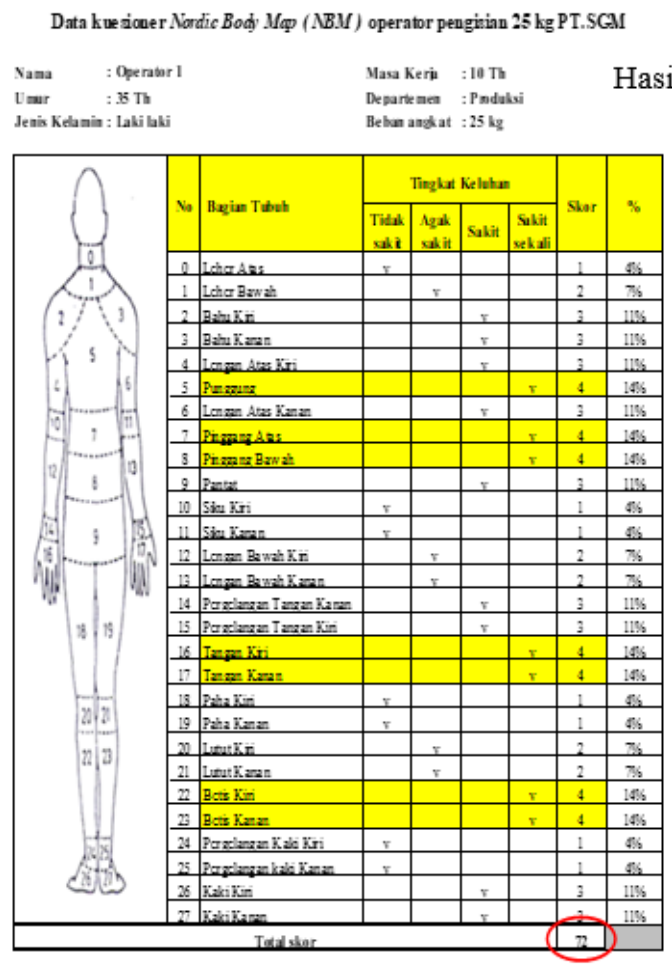

\begin{tabular}{|c|c|c|c|}
\hline $\begin{array}{l}\text { Skala } \\
\text { Likert }\end{array}$ & $\begin{array}{l}\text { Total Skor } \\
\text { individu }\end{array}$ & $\begin{array}{l}\text { Tingkat } \\
\text { resilks }\end{array}$ & Tindakan perbaikan \\
\hline 1 & $28-49$ & Rendah & Behum diperblan ad anya tind akan perb aikan \\
\hline 2 & $50-70$ & Sedarg & $\begin{array}{l}\text { Mungkindipertukan adarnya tind alkan } \\
\text { Dethaikan }\end{array}$ \\
\hline 3 & $71-91$ & Tinggi & Diperlukan tindakan perbaikan segera \\
\hline 4 & $92-112$ & Sangat tinggi & $\begin{array}{c}\text { Dipertukan ind akan perbaikan menyehruh } \\
\text { sesegera mungkin }\end{array}$ \\
\hline
\end{tabular}

\begin{tabular}{|c|c|c|c|c|c|c|c|c|}
\hline & \multicolumn{2}{|c|}{ Grup 1 } & \multicolumn{2}{c|}{ Grup 2 } & \multicolumn{2}{c|}{ Grup 3 } & \multicolumn{2}{c|}{ Grup 4 } \\
\cline { 2 - 8 } & $\begin{array}{c}\text { Op } \\
1\end{array}$ & $\begin{array}{c}\text { Op } \\
2\end{array}$ & $\begin{array}{c}\text { Op } \\
1\end{array}$ & $\begin{array}{c}\text { Op } \\
2\end{array}$ & $\begin{array}{c}\text { Op } \\
1\end{array}$ & $\begin{array}{c}\text { Op } \\
2\end{array}$ & $\begin{array}{c}\text { Op } \\
1\end{array}$ & Op 2 \\
\hline $\begin{array}{l}\text { Skor per } \\
\text { operator }\end{array}$ & $\mathbf{7 2}$ & $\mathbf{8 0}$ & $\mathbf{8 6}$ & $\mathbf{8 2}$ & $\mathbf{7 5}$ & $\mathbf{7 9}$ & $\mathbf{8 0}$ & $\mathbf{7 6}$ \\
\hline $\begin{array}{c}\text { Skor } \\
\text { rata-rata }\end{array}$ & \multicolumn{4}{|c|}{$\mathbf{7 8 . 7 5}$} \\
\hline $\begin{array}{c}\text { NBM } \\
\text { Skor }\end{array}$ & $\begin{array}{c}\text { Tingkat } \\
\text { resiko }\end{array}$ & \multicolumn{4}{|c|}{ Tindakan perbaikan } \\
\hline $28-49$ & Rendah & \multicolumn{4}{|c|}{$\begin{array}{c}\text { Belum diperlukan adanya tindakan } \\
\text { perbaikan }\end{array}$} \\
\hline $50-70$ & Sedang & \multicolumn{4}{|c|}{$\begin{array}{c}\text { Mungkin diperlukan adanya tindakan } \\
\text { perbaikan }\end{array}$} \\
\hline $71-91$ & Tinggi & \multicolumn{4}{|c|}{ Diperlukan tindakan perbaikan segera } \\
\hline & Sangat \\
\hline $92-112$ & \multicolumn{4}{|c|}{$\begin{array}{c}\text { Diperlukan tindakan perbaikan } \\
\text { menyeluruh sesegera mungkin }\end{array}$} \\
\hline
\end{tabular}

Gambar 6. Keluhan sakit operator setelah bekerja 
$25 \mathrm{~kg}$ dilakukan dengan menggunakan kuisioner NBM (Nordic Body Map).

Kuesioner NBM membagi tubuh menjadi nomor 0 sampai 27 dari leher hingga kaki yang akan mengestimasi tingkat keluhan MSDs yang dialami operator. Kuisioner Nordic merupakan kuisioner yang paling sering digunakan untuk mengetahui ketidaknyamanan atau kesakitan pada tubuh. Pengisian kuisioner ini dilakukan oleh semua operator pengisian $25 \mathrm{~kg}$ SGM secara menyeluruh. Masing-masing kuisioner dari operator dihitung skor akhirnya berdasarkan keluhan individu. Kuisioner ini menggunakan dasar pembagian gambar anatomi tubuh manusia menjadi 9 bagian utama yaitu (Tarwaka \& Sudiajeng, 2004): Leher/neck (bagian tubuh nomor 0 dan 1), Bahu/shoulder (bagian tubuh nomor 2 dan 3), Punggung bagian atas/upper back (bagian tubuh nomor 5), Siku/elbow ( bagian tubuh nomor 4, 6, 10, dan 11), Punggung bagian bawah (bagian tubuh nomor 7 dan 8), Pergelangan tangan/tangan (bagian tubuh nomor 14, 15, 16, dan 17), Pinggul/paha (bagian tubuh nomor 9,18, dan 19), Lutut (bagian tubuh nomor 20, 21, 22, dan 23) dan Tumit/kaki (bagian tubuh nomor 24, 25, 26, dan 27). Pembagian tersebut dapat dilihat seperti pada Gambar 5.

Hasil pengisian kuisioner atas semua keluhan sakit yang dirasakan operator setelah bekerja dapat, disajikan pada Gambar 6. Hasil analisis keluhan kesakitan operator menggunakan metode NBM (Nordic Body Map) menunjukkan nilai rata-rata 71-91 (skala 28 -112) dan tergolong tinggi. Nilai ini menunjukkan perlunya perbaikan segera agar tidak terjadi keluhan penyakit akibat kerja.
Tabel 6. Data anthropometri tubuh operator

\begin{tabular}{|c|c|c|c|c|}
\hline Grup & Identitas Operator & $\begin{array}{l}\text { TSB } \\
(\mathrm{cm})\end{array}$ & $\begin{array}{c}\text { LB } \\
(\mathrm{cm})\end{array}$ & $\begin{array}{c}\text { DG } \\
(\mathrm{cm})\end{array}$ \\
\hline \multirow{2}{*}{1} & Operator 1 & 105 & 41 & 4 \\
\hline & Operator 2 & 99 & 39 & 3 \\
\hline \multirow{2}{*}{2} & Operator 1 & 97 & 41 & 3,5 \\
\hline & Operator 2 & 99 & 42 & 3,5 \\
\hline \multirow{2}{*}{3} & Operator 1 & 102 & 41 & 4 \\
\hline & Operator 2 & 100 & 39 & 4 \\
\hline \multirow{2}{*}{4} & Operator 1 & 98 & 38 & 3,5 \\
\hline & Operator 2 & 96 & 38 & 3 \\
\hline & Rata- rata & 99,5 & 39,87 & 3,6 \\
\hline
\end{tabular}

Keterangan :

1. TSB : tinggi siku berdiri adalah ukuran tinggi siku dari lantai pada posisi berdiri

2. LB : lebar bahu adalah ukuran lebar bahu diukur dari depan dada

3. DG : diameter genggaman tangan adalah ukuran permukaan tangan jika posisi menggenggam

Untuk mengatasi masalah tersebut, berdasarkan analisis kelelahan untuk rancangan jenis alat bantu dengan metode NBM, NASA-TLX, dan REBA, maka perlu dilakukan perancangan sebuah alat bantu material handling. Dengan banyaknya jenis, ukuran dan bentuk alat bantu angkat di pasaran, maka diperlukan spesifikasi alat bantu angkat berdasarkan data anthropometri tubuh dari operator. Dari hasil pengukuran tubuh yang berhubungan dengan aktivitas angkat dan pemindahan, maka diperoleh ukuran dimensi tubuh operator seperti dalam Tabel 6.

Berdasarkan data pada Tabel 6, selanjutnya diperoleh rancangan alat angkat troli seperti Gambar 7 dengan sistem kerja baru sebagai berikut:

1. Operator mengambil troli, yang dirancang menjadi 3 lapisan yang terdiri dari lapisan atas
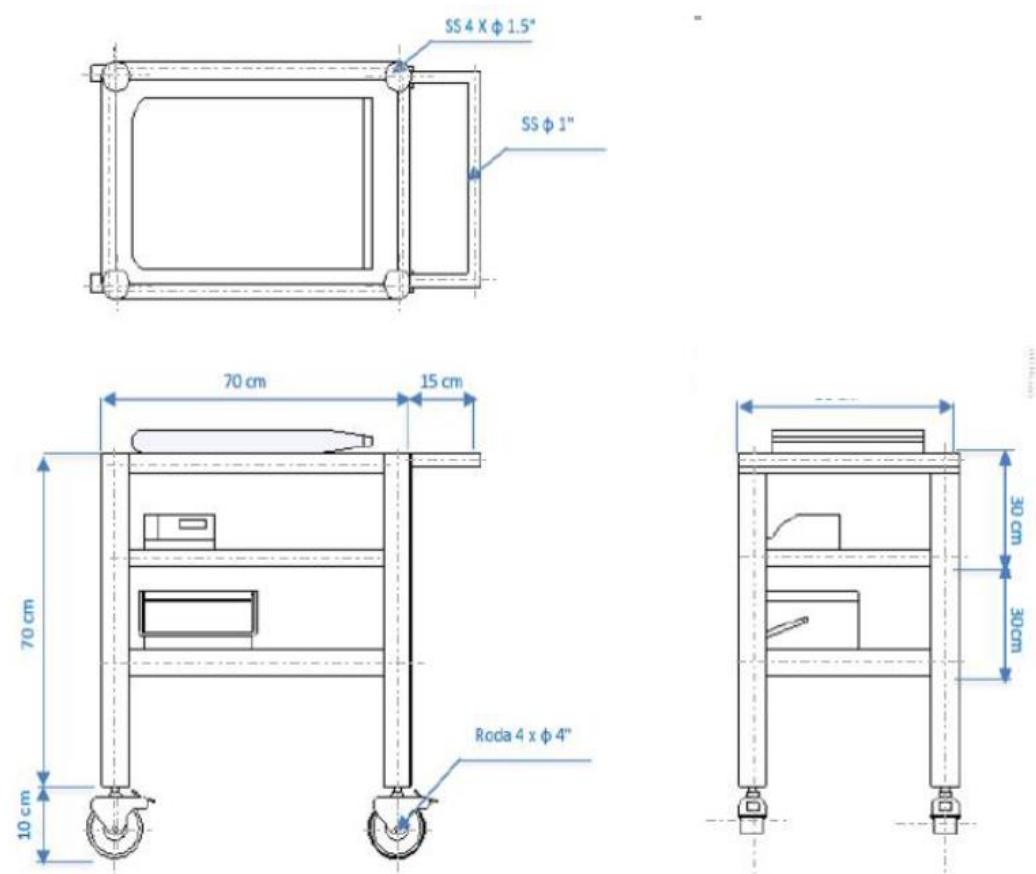

Gambar 7. Gambar teknik rancangan alat angkat troli 
untuk meletakkan kemasan susu bubuk $25 \mathrm{~kg}$ lapisan tengah untuk membawa peralatan pengetes hasil perekatan dan dilapis paling bawah untuk menempatkan kotak sampel. Troli yang berisi peralatan pengetesan hasil perekatan dibawa ke dekat conveyor. Selanjutnya pekerja memindahkan kemasan zak dari conveyor ke troli sisi atas.

2. Aktivitas pengecekan hasil dilakukan setelah kemasan zak diletakkan di troli sisi atas (rak atas).

3. Setelah dilakukan pengecekan, hasil perekatan dikembalikan lagi ke conveyor

Untuk menghindari potensi cidera punggung (Low Back Pain), operator pengisian $25 \mathrm{~kg}$ dapat melakukan aktivitas pengetesan hasil perekatan seperti berikut:

1. Berdiri dengan posisi tegak, baik posisi kaki, badan, lengan atas, dan leher agar beban ditopang oleh seluruh anggota tubuh.

2. Menggunakan sarung tangan latex yang tidak licin agar tangan operator tetap terjaga kebersihan dalam menyentuh produk dan aman dalam proses pengangkatan kemasan zak.

3. Melakukan gerakan gerakan relaksasi pada jam istirahat sehingga tubuh terasa lebih segar. Sebaiknya operator beristirahat setiap 5 menit setelah bekerja 30 menit untuk memulihkan kekuatan otot.

4. Pengaturan personil secara bergantian saat pengecekan hasil perekatan dalam tiap shiftnya sehingga beban pengangkatan merata ke setiap operator.

Penggunaan alat bantu angkat mengindikasikan adanya penghematan waktu pengecekan hasil perekatan. Jumlah kemasan zak yang dihasilkan mesin pengisian susu bubuk pada akhirnya meningkat, sehingga produktivitas operator juga meningkat seperti yang terlihat pada Gambar 8.

Analisis peningkatan produktivitas pengisian susu bubuk per shift dilanjutkan dengan menggunakan Uji Hipotesa $T$ dengan jumlah sampel sebanyak $n=30$ sampel (Tabel 7).

Kriteria penerimaan uji hipotesis:

1. $\mathrm{H}_{0}: \mu_{1}=\mu_{2}$ (Jumlah pengisian kemasan zak sebelum dan sesudah menggunakan troli adalah

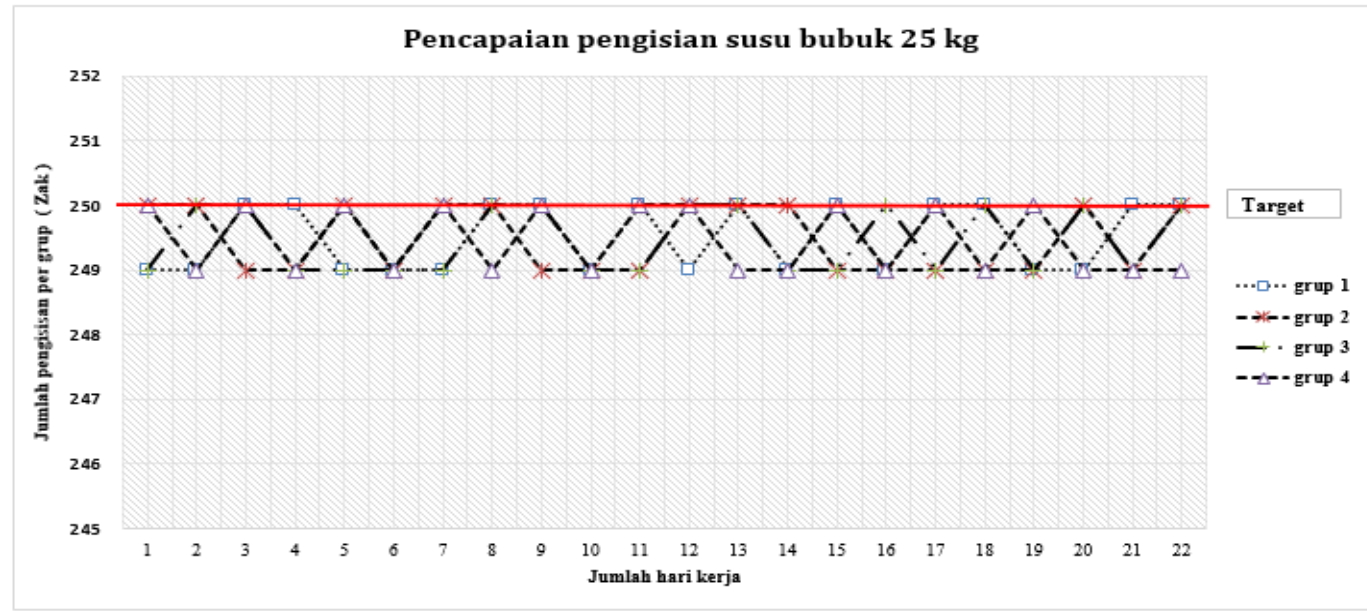

Gambar 8. Grafik pencapaian target produksi setelah penggunaan troli hasil rancangan

Tabel 7. Data produksi sebelum dan sesudah menggunakan alat angkat

\begin{tabular}{|c|c|c|c|}
\hline $\begin{array}{c}\text { Sampel } \\
\text { per } \\
\text { shift }\end{array}$ & $\begin{array}{c}\text { Jumlah } \\
\text { zak } \\
\text { sebelum } \\
\text { memakai } \\
\text { trolley }\end{array}$ & $\begin{array}{c}\text { Jumlah zak } \\
\text { sesudah } \\
\text { memakai } \\
\text { trolley }\end{array}$ & selisih \\
\hline 1 & 202 & 248 & 46 \\
\hline 2 & 200 & 250 & 50 \\
\hline 3 & 190 & 250 & 60 \\
\hline 4 & 195 & 248 & 53 \\
\hline 5 & 207 & 248 & 41 \\
\hline 6 & 207 & 249 & 42 \\
\hline 7 & 204 & 249 & 45 \\
\hline 8 & 210 & 250 & 40 \\
\hline 9 & 200 & 250 & 50 \\
\hline 10 & 203 & 249 & 46 \\
\hline 11 & 206 & 249 & 43 \\
\hline 12 & 200 & 250 & 50 \\
\hline 13 & 210 & 250 & 40 \\
\hline 14 & 200 & 249 & 49 \\
\hline 15 & 201 & 249 & 48 \\
\hline
\end{tabular}

\begin{tabular}{|c|c|c|c|}
\hline $\begin{array}{c}\text { Sampel } \\
\text { per } \\
\text { shift }\end{array}$ & $\begin{array}{c}\text { Jumlah } \\
\text { zak } \\
\text { sebelum } \\
\text { memakai } \\
\text { trolley }\end{array}$ & $\begin{array}{c}\text { Jumlah } \\
\text { zak } \\
\text { sesudah } \\
\text { memakai } \\
\text { trolley }\end{array}$ & selisih \\
\hline 16 & 207 & 250 & 43 \\
\hline 17 & 205 & 249 & 44 \\
\hline 18 & 204 & 250 & 46 \\
\hline 19 & 206 & 249 & 43 \\
\hline 20 & 203 & 250 & 47 \\
\hline 21 & 203 & 249 & 46 \\
\hline 22 & 204 & 250 & 46 \\
\hline 23 & 200 & 249 & 49 \\
\hline 24 & 207 & 249 & 42 \\
\hline 25 & 205 & 250 & 45 \\
\hline 26 & 205 & 250 & 45 \\
\hline 27 & 200 & 249 & 49 \\
\hline 28 & 206 & 249 & 43 \\
\hline 29 & 207 & 250 & 43 \\
\hline 30 & 204 & 250 & 46 \\
\hline
\end{tabular}


sama)

2. $\mathrm{H}_{1}: \mu_{1} \neq \mu_{2}$ (Jumlah pengisian kemasan zak sebelum dan sesudah menggunakan troli adalah tidak sama)

3. Terima $\mathrm{H}_{0}$ jika $t_{\text {hitung }} \leq t_{\text {tabel }}$ atau $p$-value $>$ alpha $(\alpha)$ 4. Tolak $\mathrm{H}_{0}$ jika $t_{\text {hitung }}>t$ tabel atau $\mathrm{p}$-value $\leq$ alpha $(\alpha)$ Perhitungan uji hipotesis $T$ sebelum dan sesudah menggunakan alat bantu angkat dihitung dengan bantuan program Microsoft Excel. Hasil pengujian disajikan pada Tabel 8. Dengan membandingkan rata-rata produksi sebelum dan sesudah pemakaian troli, maka diperoleh informasi peningkatan produksi sebesar 23,15\%.

Tabel 8. Hasil uji hipotesa

\begin{tabular}{l|l}
\hline Jumlah sampel & 30 \\
\hline $\mathrm{N}-1$ & 29 \\
\hline alpha $(\alpha)$ & 0.05 \\
\hline$t$-tabel pada df $\mathrm{N}-1$ dan alfa 0.05 & 2.0452 \\
\hline average sebelum pemakaian troli & 203.367 \\
\hline average sesudah pemakaian troli & 249.367 \\
\hline nilai rata rata selisih sebelum dan & 46.000 \\
sesudah pemakaian troli & 4.177 \\
\hline standart deviasi & 60.317 \\
\hline$t$-hitung & ada perbedaan signifikan \\
\hline Kesimpulan uji Hipotesis & Ho ditolak \\
\hline Terima $\mathrm{H}_{0}$ jika $t_{\text {hitung }} \leq t_{\text {tabel }}$ & \\
\hline Tolak $\mathrm{H}_{0}$ jika $t_{\text {hitung }}>t_{\text {tabel }}$ & \\
\hline
\end{tabular}

Perhitungan prosentase peningkatan waktu pengetesan/zak =

$\frac{\text { waktu sebelum pakai trolley-waktu sesudah pakai trolley }}{\text { waktu sebelum pahai trolleny }} \times 100 \%$

$=\frac{5-3}{5} \times 100 \%=40 \%$

Prosentase peningkatan pengisian $/ \mathrm{zak}=$

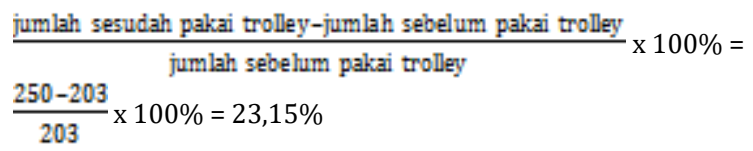

\section{PENUTUP}

Memperhatikan anthropometri pekerja di SGM, dimensi alat angkat troli hasil rancangan adalah dengan tinggi pegangan troli 99,5 cm, lebar pegangan troli $39,87 \mathrm{~cm}$ dan diameter pegangan troli $3,60 \mathrm{~cm}$. Setelah alat angkat hasil rancangan diaplikasikan dalam aktivitas material handling, dengan menggunakan uji hipotesa $t$ dan tingkat kepercayaan 95\% dapat diyakini adanya peningkatan produktivitas pengisian susu bubuk kemasan $25 \mathrm{~kg}$ sebesar $23,15 \%$.

\section{DAFTAR PUSTAKA}

Hart, S. G., \& Staveland, L. E. (1988). Development of NASA-TLX (Task Load Index): Results of empirical and theoretical research. In Advances in psychology (Vol. 52, pp. 139183). Elsevier.

Hignett, S., \& McAtamney, L. (2000). Rapid entire body assessment (REBA). Applied Ergonomics, 31(2), 201-205.

Nurmianto, E. (2003). Ergonomi Konsep Dasar dan Aplikasinya Edisi Pertama. Guna Widya, Surabaya.

Restantin, N. Y., Ushada, M., \& Ainuri, M. (2012). Desain prototipe meja dan kursi pantai portabel dengan integrasi pendekatan ergonomi, value engineering dan kansei engineering. Jurnal Teknik Industri, 14(1), 53-62.

Soewarno, A. (2005). Perbaikan lingkungan kerja Pada pengrajin ukiran kelongsong peluru dengan menyesuaikan tinggi meja kerja Di desa kamasan, klungkung. Jurnal Permukiman Natah, 3(2).

Sutalaksana, I. Z. (2006). Teknik Tata Cara Kerja. Laboratorium Tata Cara Kerja dan Ergonomi. Bandung: Dept. Teknik Industri-ITB.

Tarwaka, S., \& Sudiajeng, L. (2004). Ergonomi untuk keselamatan, kesehatan kerja dan produktivitas. UNIBA, Surakarta. 